\title{
Comparison of seismic sources for shallow seismic: sledgehammer and pyrotechnics
}

\author{
Aleksander Brom*, Iwona Stan-Kłeczek \\ Department of Applied Geology, Faculty of Earth Sciences, University of Silesia, 60 Bedzinska Str, 41-200 \\ Sosnowiec, Poland; \\ corresponding author: aleksander.brom@gmail.com
}

Received: $27^{\text {th }}$ October, 2015

Accepted: $3^{\text {rd }}$ November, 2015

\begin{abstract}
The pyrotechnic materials are one of the types of the explosives materials which produce thermal, luminous or sound effects, gas, smoke and their combination as a result of a self-sustaining chemical reaction. Therefore, pyrotechnics can be used as a seismic source that is designed to release accumulated energy in a form of seismic wave recorded by tremor sensors (geophones) after its passage through the rock mass. The aim of this paper was to determine the utility of pyrotechnics for shallow seismic engineering. The work presented comparing the conventional method of seismic wave excitation for seismic refraction method like plate and hammer and activating of firecrackers on the surface. The energy released by various sources and frequency spectra was compared for the two types of sources. The obtained results did not determine which sources gave the better results but showed very interesting aspects of using pyrotechnics in seismic measurements for example the use of pyrotechnic materials in MASW.
\end{abstract}

Key words: pyrotechnic material, seismic refraction method, P-wave velocity

\section{Introduction}

Elastic wave generated by pyrotechnic materials is not precisely discussed in literature. Explosive charges detonated in shot holes were used for deep seismic exploration (Staples et al 1999; Suarez and Stewart 2008), e.g. during hydrocarbons prospection using seismic reflection method. Another concern is the necessity of having sufficient and competent project coordinators as well as a vast amount of money. In shallow investigation does not use explosives because of the simplification methods, reduce costs, protect the environment, and the lack of high expectations in terms of energy sources.

Pyrotechnics were used in Johnsons Glacier studies by Benjumea and Teixidó (2001). Authors justify used of firecrackers as promising seismic source. Applied of firecrackers were dictated by preferable signalto-noise ratio, more intensive amplitudes of signal, wider frequency spectrum than the same parameters obtained using SISSY source. Similar studies were performed by Miyamachi in 1984 (Miyamachi et al 1987). The subject of the research was Showa-Shinzan lava dome, investigated with fireworks fired on the occasion of summer festival. Authors did not compare fireworks with other sources of seismic wave but interpreted received results.

Dao-Tze Tsai, Chien-Ying Wang and Rong-Kuan Yang (1990) compared selfdesigned tool that uses firecrackers with Dynasource and sledgehammer as a source for shallow seismic. They have found that despite lower energy level, adequate high frequency and high quality signals were generated. This 
type of source was used in fault detection (Chien-Ying Wang and Rong-Kuan Yang DaoTze Tsai 1991) and it proved the feasibility of firecracker source.

The small number of references was a driving force for writing this paper focused on comparison between conventional shallow seismic source like hammer and rarely used source namely firecracker and define convenience of use of common available explosives (firecrackers) for seismic purposes..

\section{Seismic sources}

The selection of proper seismic source that meets requirements and goals of shallow seismic surveys have influence on project's efficiency. Selected seismic source should have strong signal with specific frequency response and should allow to achieve expected depth and simultaneously provide the highest possible resolution of recorded signal (Kearey et. al. 2002). The force of source depends on a large number of factors such as the structure of subsurface, the age of rock formation, the lithology, the frequency response of geophone, the dynamic range of used recorder and planned depth of recognition (Steeples 2000). When seismic source is selected, features such as spectral characteristic, repeatability, convenience of use, efficiency and sufficient released energy should be considered. Safety matters are also important (Steeples 2000).

The perfect seismic source is characterized by strong amplitudes of high-frequency signal. The Earth is a type of a low-pass filter (Staples et. al. 1999) . After recording of signal that passed through rock formation, more or less flat response from zero to frequency required by exploration resolution is obtained. In connection with fact that different frequencies are attenuated differently as a function of distance, an ideal source would be ideal only for a distance between the source and the receiver.

According to seismic sources division made by Pilecki (Pilecki et al 2014) considered seismic source is active - operator detonates it himself, impulse - generates short minimumphase signal as any explosive charge, destructive - its application causes soil surface damage.

\section{Field study}

The study area is located in "Podleśna" dolomite quarry where subsurface soil layer was removed before planned further exploitation. Measurements were carried out using P.A.S.I. 16SG24 instrument. To study was used 12 geophones with $3 \mathrm{~m}$ spacing between them. Sampling time was $0.00025 \mathrm{~s}$. There were 5 shot points located at $-10 \mathrm{~m}, 0 \mathrm{~m}$, $16,5 \mathrm{~m}, 33 \mathrm{~m}, 43 \mathrm{~m}$.

Research was performed with a hammer weighing 8 kilos hitting again in metal plate and using firecrackers FP3 with $3.0 \mathrm{~g}$ of Net Explosive Content (NEC) (Fig.1), distributed in Poland by Jorge Sp. z o.o. and manufactured in China.

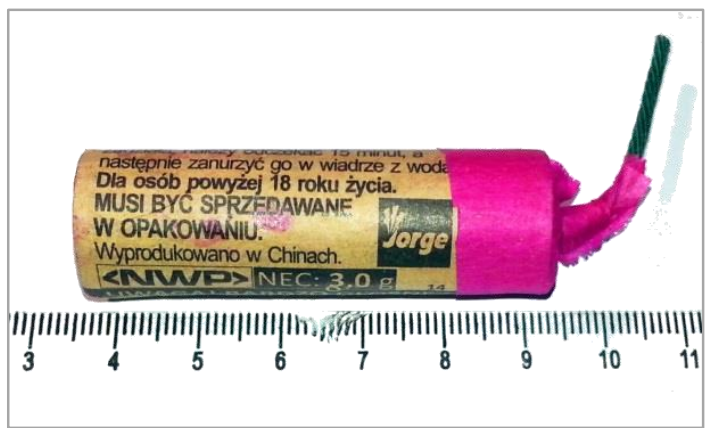

Fig. 1. The example of firecracker FP3 (fot. A.Brom).

The explosive materials were detonated on the surface. The presented studies required the using of metal housing that steered the shock wave of firecracker from blast towards ground.

The author designed conical shaped cover (Fig.2A). Its dimensions are: base diameter $500 \mathrm{~mm}$, height $-170 \mathrm{~mm}$. In order to avoid unwanted vibrations in the event of taking the cover off the ground and falling down, the cover was temporarily fitted to the ground with four 
35-centimetre rods nailed down before the shooting. The metal cover was weighted with 20-kilo bag with sand for safety reasons (Fig.2B).

\section{Results}

Collected traces were processed using SeisImager $/ 2 \mathrm{D}^{\mathrm{TM}}$ software. It contain from two modules, the first - Pickwin offer the possibility of pick first breaks of wave and user is able to do Fourier analysis of signal, the second Plotrefa allow to create hodograph and then generate model of geological layers.

It is necessary to set the parameters 'gain' and 'scale' properly so as to get right comparison of traces using PickWin. Otherwise the program normalises traces in order to increase the data visibility even though amplitudes close to the source are much greater than amplitudes recorded by rearmost geophone. In this case 'gain' and 'scale' coefficients were 0.03 and 0.05 respectively. The same parameters applied to each section makes evaluation of seismic source energy possible.

Figures 3 and 4 show ground vibration recorded by geophones. Both figures present first $400 \mathrm{~ms}$. More powerful surface wave can be seen in the figure 4 representing seismic wave generated by firecracker. This wave can be clearly distinguished due to extremely high amplitude.
The problem of calculating released energy proved impossible to resolve. It can be only estimated. Yordkayhun and Na Suwan (2012) show that energy produced during explosion was bigger than energy released in blow of hammer.

Frequency spectra of two hammer strokes are presented below. Figure 5 depicts midprofile registration $(16.5 \mathrm{~m})$ while figure 6 presents images generation at offset $(-10 \mathrm{~m})$.

Analysing these spectra, frequency windows of sledgehammer's blow can be easily seen. Impact source is bimodal - there can be observed two windows with the highest amplitudes, first at $50-60 \mathrm{~Hz}$ and another one at $100-110 \mathrm{~Hz}$

Presented figures signalize what kind of filter is soil and rock mass. The decrease of frequency with distance can be seen on both spectra.

Maximal amplitudes (dominant frequency) of sledgehammer blows are within 50-60 Hz. When energy is released in the middle of the array, the highest frequency peak aims towards lower frequencies and finally reaches circa $50 \mathrm{~Hz}$. While blow is at $-10 \mathrm{~m}$, geophones at opposite side of array record frequencies even lower than $50 \mathrm{~Hz}$.

The relationship between dominant frequency in correlation with geophone-source distance resembles reversed function of recording time and distance (hodograph).

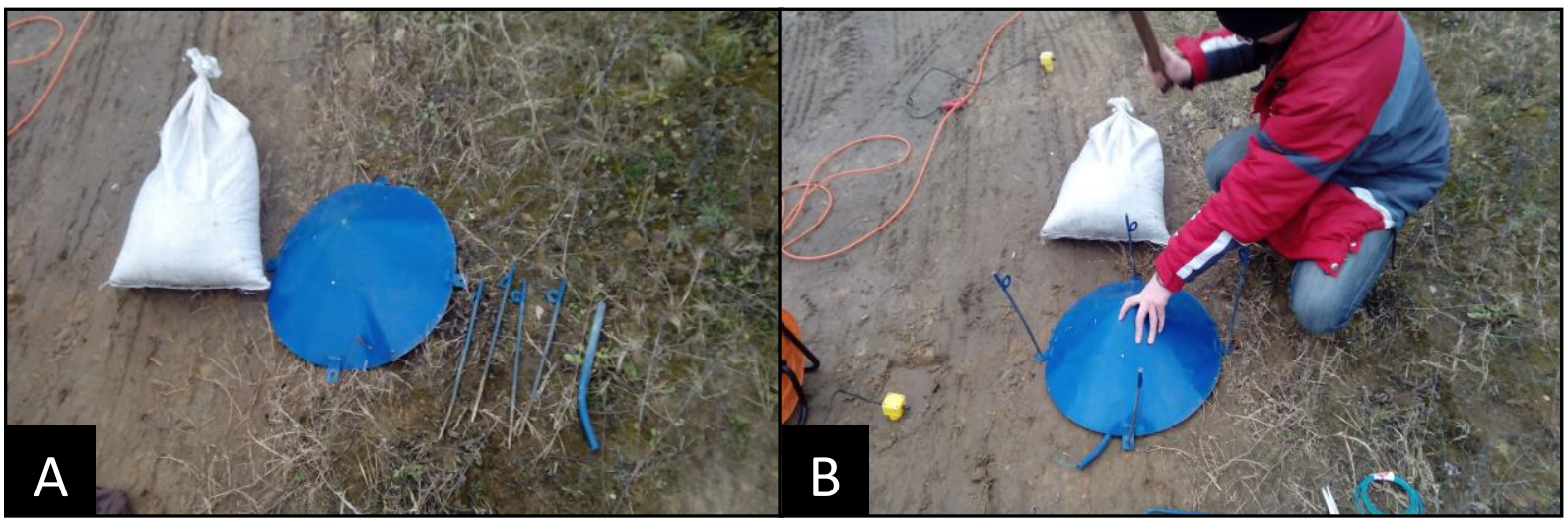

Fig. 2. The metal housing with rods (A) and the way of protection (fot. I.Stan-Kłeczek). 


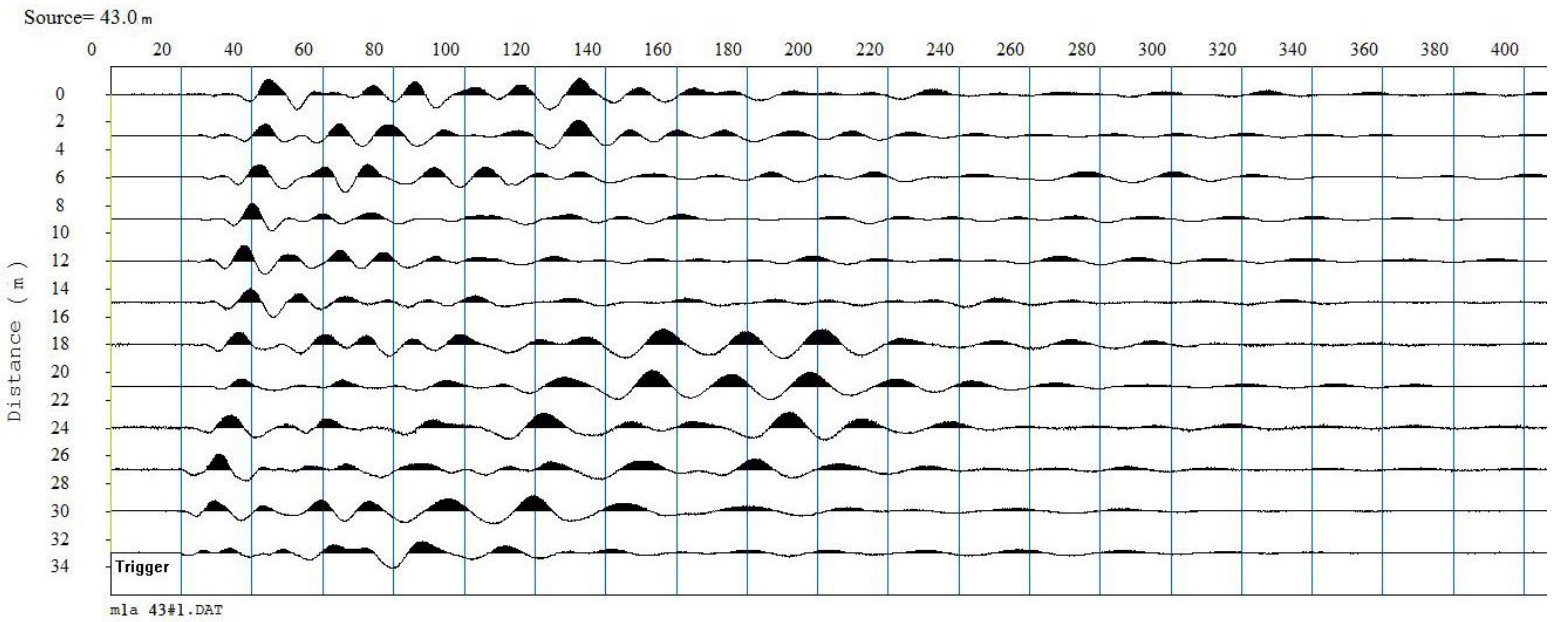

Fig. 3. Ground vibration produced by hammer recorded by geophones. The seismic source was located at $43 \mathrm{~m}$.

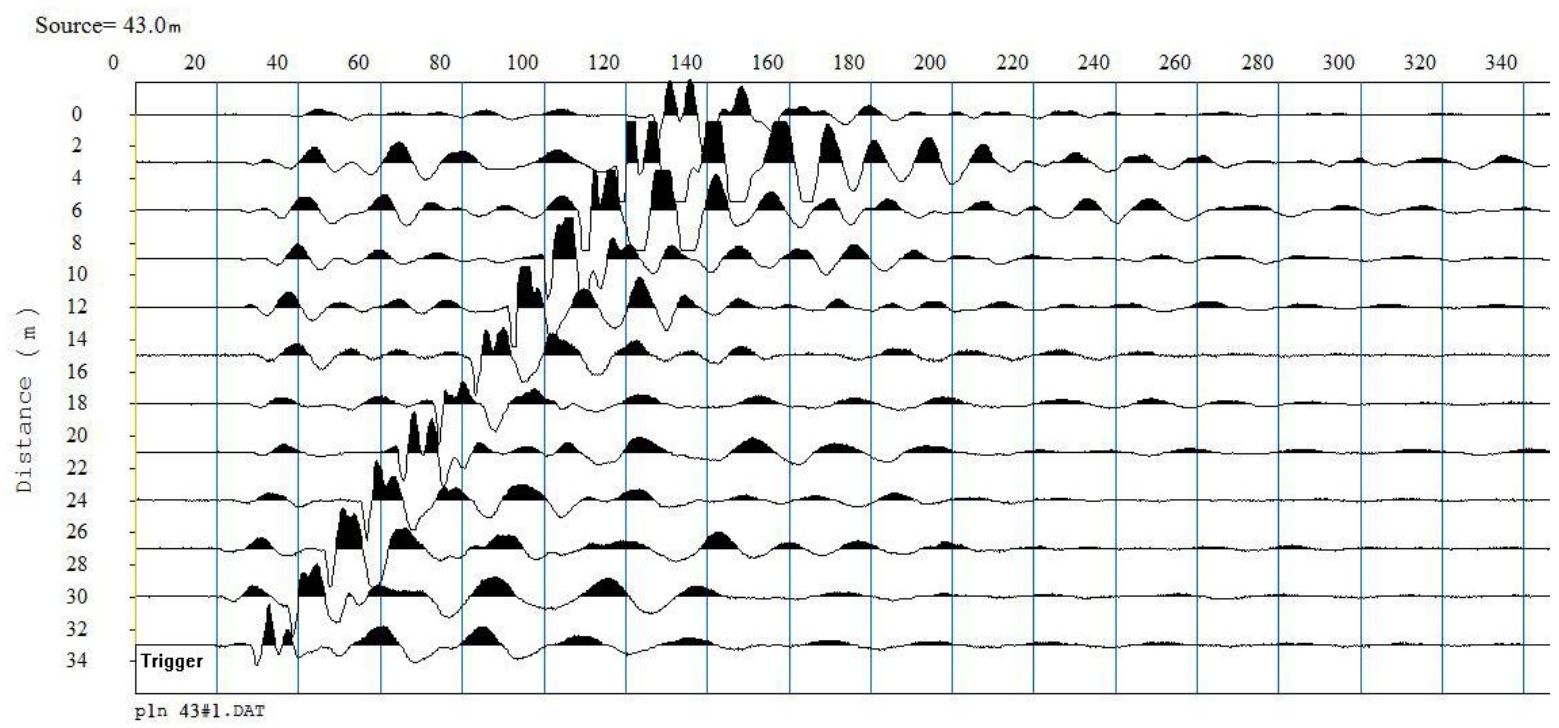

Fig. 4. Ground vibration produced by firecracker recorded by geophones. The seismic source was located at $43 \mathrm{~m}$.

Observed amplitude spectra of firecracker's detonation shows its multimodal nature. It would be overstatement to say that the spectrum is continuous but the band is definitely wider. Frequency distribution is characterised by multiplied maxima. The highest amplitudes are noticeable grouped. First 'maxima pack' could be seen between 50 and $90 \mathrm{~Hz}$ and another between 150 and $190 \mathrm{~Hz}$.
Characteristic feature of obtained sledgehammer records is the absence of frequencies higher than $100 \mathrm{~Hz}$ compared to the firecracker. Miller et al. (1986) ascertained that the presence of the second maximum of higher frequency is distinctive for explosives. Explosive charges commonly used in engineering seismic release seismic energy within range of 100 to $200 \mathrm{~Hz}$, some of them reach even $400 \mathrm{~Hz}$. 


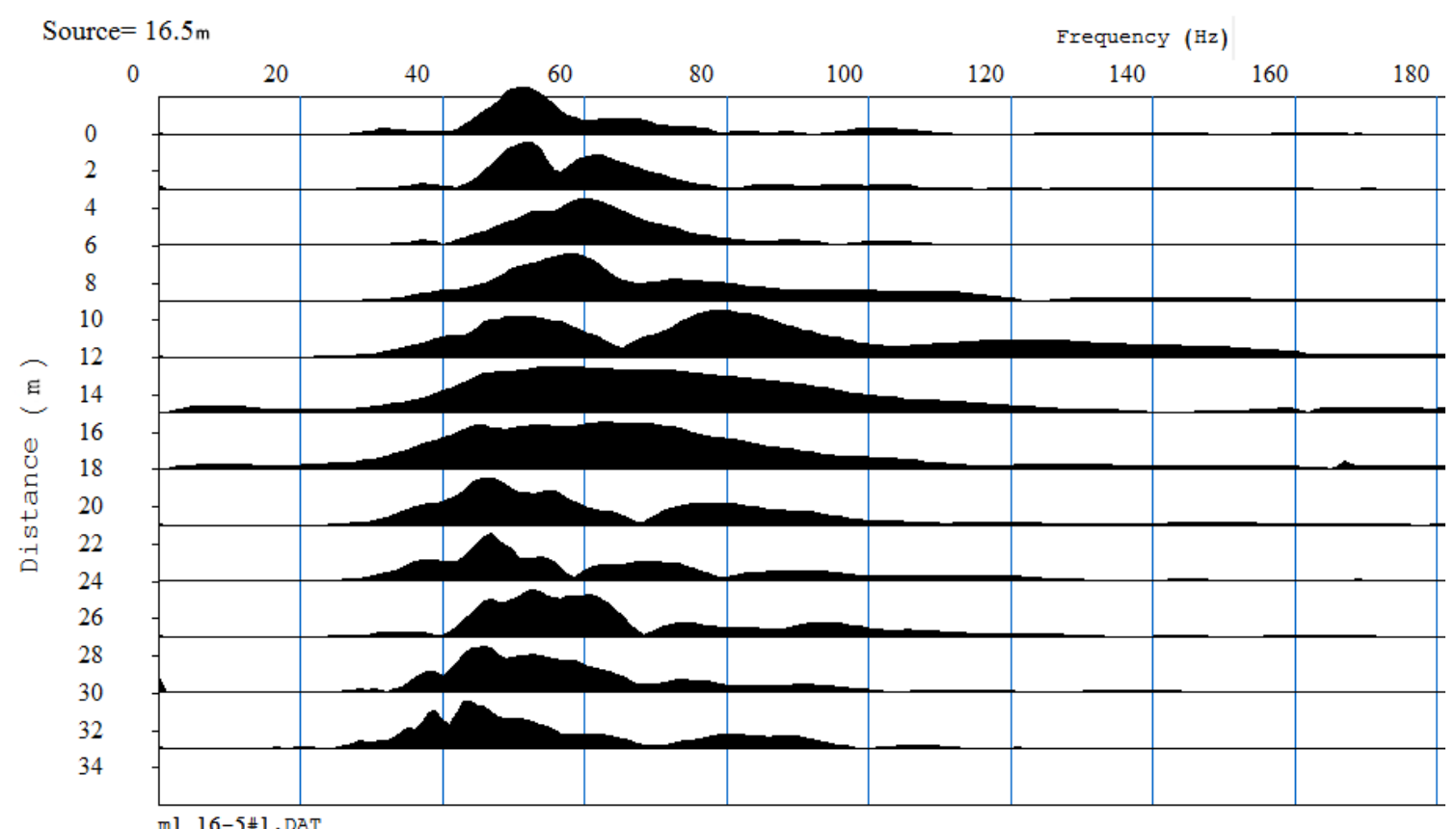

Fig. 5. Frequency spectra of hammer blow at $16.5 \mathrm{~m}$.

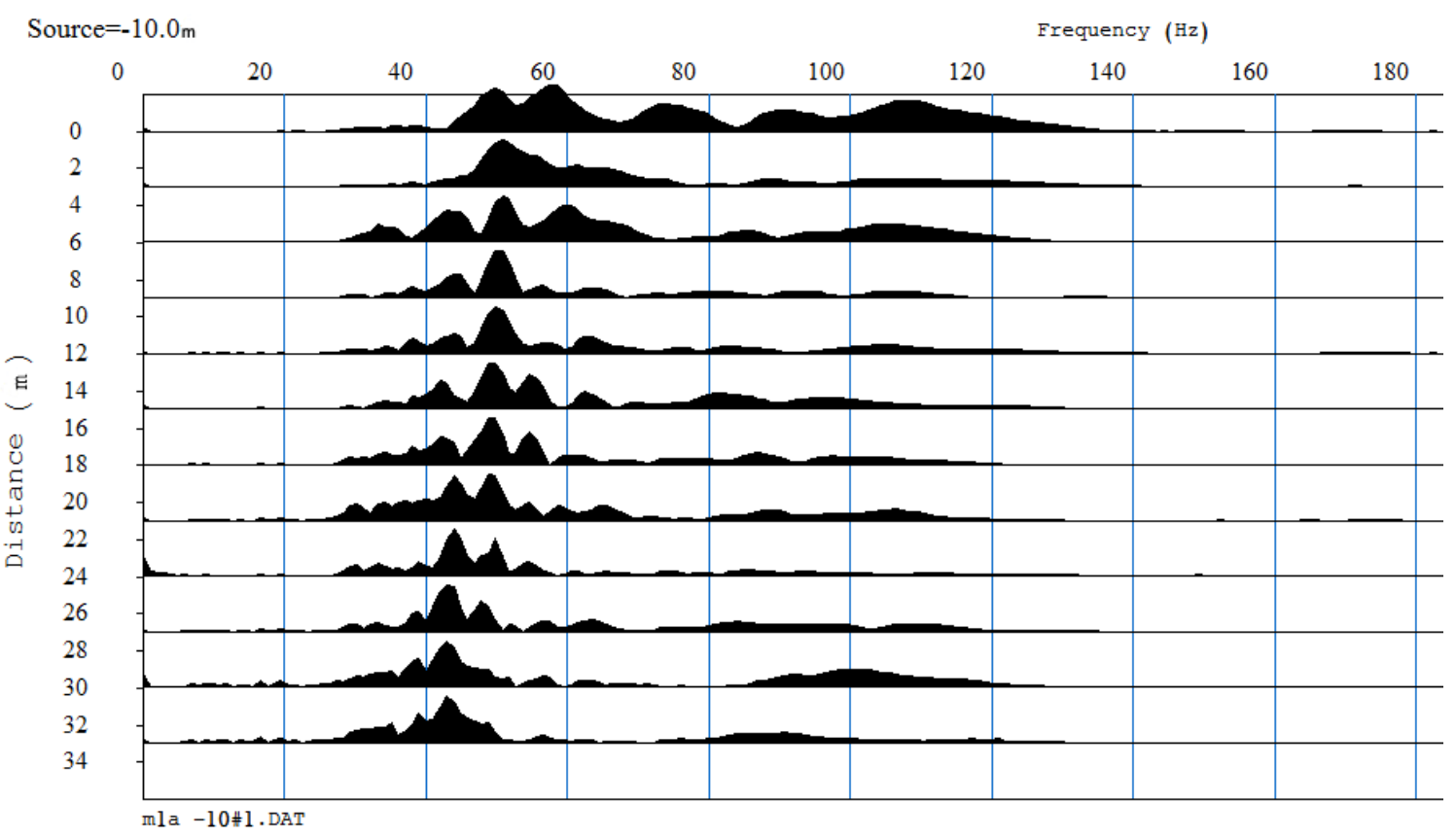

Fig. 6. Frequency spectra of hammer blow at $-10.0 \mathrm{~m}$.

\section{Discussion}

During selecting seismic source it is very important the cost, spectral characteristic, repeatability, use convenience, efficiency and energy. The safety must be also taken into account.

The use of sledgehammer is costless apart from purchase cost. The cost of pyrotechnic, similar to this used in presented study is about 0.60PLN.

\section{OPEN}




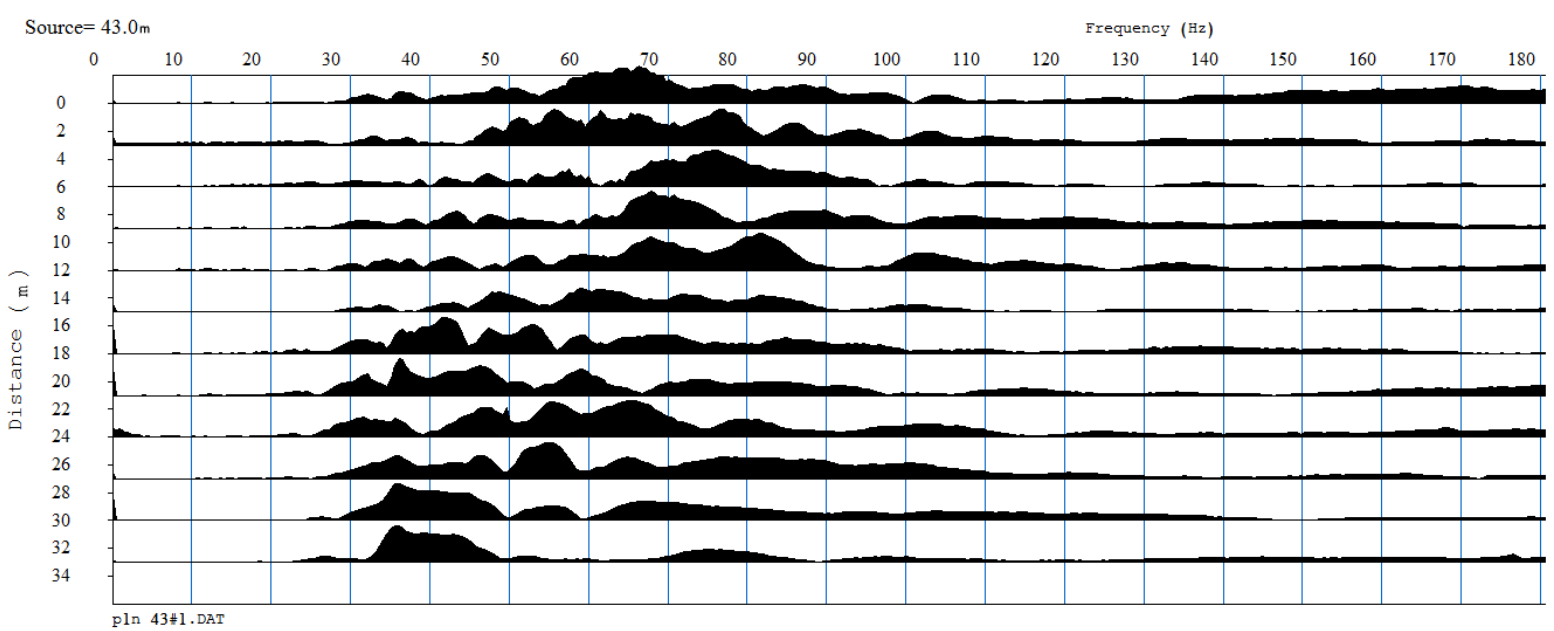

Fig. 7. Frequency spectra of firecracker blast at $43.0 \mathrm{~m}$.

Therefore it is easy to calculate the cost of pyrotechnics used in one profile. It costs 3.00PLN and it is not a prohibitive if bear in mind possible advantages.

Firecrackers give maximum amplitudes for frequencies between 50 and $90 \mathrm{~Hz}$, while sledgehammer has dominant frequencies on 50$60 \mathrm{~Hz}$ level. However, it is possible to slightly increase this level. To enhance dominant frequency of sledgehammer blow it is necessary to reduce its weight and use the more rigid metal plate. Unfortunately it is not possible to measure the size of the amplitude using SeisImager program.

The spectrum changes with distance from source. Near the source a spectrum composes of wide frequency band with some modes and then some amplitudes decay or disappear (in general, higher frequency) with distance. Application of pyrotechnics as a source of seismic wave is related to repeatability problems. Hammer blow advantage is quite good repeatability if following impacts are made by the same person. Different body shape can hinder or even incapacitate receiving signal of the same seismic energy (Rubin et al 2012). In contrast, looking alike firecrackers does not need to contain the same explosive content. Specified
NEC does not ensure the same energy, but significantly reduces differences.

Influence of described source on environment is nearly negligible as well as sledgehammer. Qualifying source as disruptive only due to being explosive is an overstatement. If firecracker was placed on grass, it would be slightly burnt. On the other hand if it was placed on solid ground without vegetation, there should be no remnants. Remains left by firecracker are very fine. The firecracker covers are made of paper thus they are biodegradable.

Improvement of signal-to-noise ratio (S-N), and thereby data quality, is made by stacking sequent records gathered from the same shot point. The ten-fold increase of S-N ratio needs about 100 blow repetitions. Presented data were not stacked because there was a single shot at the shot point. Collected traces reveal that energy of the firecracker is greater than energy of the hammer.

\section{Conclusions}

Tentatively, invented and described in this paper explosive seismic source is suitable for shallow engineering seismic purposes. It is likely to achieve even better resolution of section owing to the presence of high frequency 
signal but only using seismic reflection method. Another surveys and improvements of instrumentation are necessary to solve the problem of usability of such source completely.

Moreover, it is very important to remember that manufacturer did not design this product as seismic source. Large proportion of explosion energy is distributed in rock mass as surface wave hence may be a subject of interest of Multichannel Analysis of Surface Waves. Experiments applying this technology are planned to be performed in the future.

\section{References}

Benjumea B., Teixidó T. (2001) Seismic reflection constraints on the glacial dynamics of Johnsons Glacier, Antarctica. Journal of Applied Geophysics. 46, 31-44.

Kearey P., Brooks M., Hill I. (2002) An Introduction to Geophysical Exploration, Blackwell Science Ltd, Third Edition.

Miller R. D., Pullan S. E., Waldner J. S., Haeni F. P. (1986) Field comparison of shallow seismic sources. Geophysics, 51, 11, 20672092.

Miyamachi H., Watanabe H., Moriya T., Okada H. (1987) Seismic Experiments on ShowaShinzan Lava Dome Using Firework Shots. PAGEOPH. 125, 6, 1025-1037.

Pilecki Z., Harba P., Czarny R., Cielesta Sz., Pszonka J. (2014) Źródła drgań w sejsmice inżynierskiej. Przegląd Górniczy, 7, 22-31 (in Polish).
Rubin M.J., Camp T., van Hervijnen A., Schweizer J. (2012) Automatically detecting avalanche events in passive seismic data, 11th International Conference on Machine Learning and Applications (ICMLA), 1, 13-20.

Staples R.K., Hobbs R.W., White R.S. (1999) A comparison between airguns and explosives as wide-angle seismic sources, Geophysical Prospecting, 47, 313-339.

Steeples Don W. (2000) A review of shallow seismic methods, Annali Di Geofisica, 43, 6.

Suarez G.M., Stewart R.R. (2008) Seismic source comparison for compressional and converted-wave generation at Spring Coulee, Alberta. Part I: Heavy vibroseisdynamite comparison. CREWES Research Report, 20, 1-15.

Tsai, D. T., Wang, C. Y., Yang, R. K. (1990). Shallow Reflection Seismics Using Firecracker as the Source, I: Firecracker. Terrestrial, Atmospheric and Oceanic Sciences, 1(4), 307-320.

Wang, C. Y., Yang, R. K., Tsai, D. T. (1991). Shallow Reflection Seismics Using Firecrackers as the Source II : Field Experiments. Terrestrial, Atmospheric and Oceanic Sciences, 2(3), 163-185.

Yordkayhun S., Na Suwan J. (2012) A university-developed seismic source for shallow seismic surveys. Journal of Applied Geophysics 82, 110-118. 